\title{
Aspiration Pneumonia: Dental and Oral Risk Factors in an Older Veteran Population
}

\author{
Margaret S. Terpenning, MD, * George W. Taylor, DMD, MPH, DrPH, ${ }^{\dagger}$ \\ Dennis E. Lopatin, PhD, ${ }^{\ddagger}$ Connie Kinder Kerr, RN, MS, ${ }^{\S}$ B. Liza Dominguez, DMD, MS, $\neq$ \\ and Walter J. Loesche, DMD, $\mathrm{PhD}^{\neq}$
}

OBJECTIVES: To investigate the importance of medical and dental factors in aspiration pneumonia in an older veteran population.

DESIGN: Prospective enrollment of subjects with retrospective analysis of data.

SETTING: Department of Veterans Affairs outpatient clinic, inpatient ward, and nursing home.

PARTICIPANTS: 358 veterans age 55 and older; 50 subjects with aspiration pneumonia.

MEASUREMENTS: Demographic and medical data; functional status; health-related behaviors; dental care utilization; personal oral hygiene; comprehensive dental examination; salivary assays including IgA antibodies; and cultures of saliva, throat, and dental plaques.

RESULTS: Two logistic regression models produced estimates of significant risk factors. One model using dentate patients included: requiring help with feeding (odds ratio $(\mathrm{OR})=13.9)$, chronic obstructive pulmonary disease $(\mathrm{COPD})(\mathrm{OR}=4.7)$, diabetes mellitus $(\mathrm{OR}=3.5)$, number of decayed teeth $(\mathrm{OR}=1.2)$, number of functional dental units $(\mathrm{OR}=1.2)$, presence of important organisms for decay, Streptococcus sobrinus in saliva ( $\mathrm{OR}=6.2)$, and periodontal disease, Porphyromonous gingivalis in dental plaque $(\mathrm{OR}=4.2)$, and Staphylococcus aureus presence in saliva $(\mathrm{OR}=7.4)$. The second model, containing both dentate and edentulous patients included: requiring help with feeding $(\mathrm{OR}=4.7)$, $\mathrm{COPD}(\mathrm{OR}=2.5)$, dia-

From the "Department of Internal Medicine, University of Michigan Medical School; ${ }^{\dagger}$ Department of Cardiology, Restorative Sciences, and Endodontics and ‡Department Biologic and Materials Sciences, University of Michigan School of Dentistry; and SUniversity of Michigan School of Nursing, Ann Arbor, Michigan.

Supported by Program Project Grant DE-09142 from the National Institutes of Health/National Institute of Dental and Craniofacial Research.

Informed consent to participate in this study was obtained from all subjects and the guidelines for human subject experimentation of the University of Michigan and the Department of Veterans Affairs were followed in the conduct of this research.

Address correspondence to Margaret S. Terpenning, MD, VA Medical Center, GRECC (11G), 2215 Fuller Road, Ann Arbor, MI 48105. betes mellitus $(\mathrm{OR}=1.7)$, and presence of $S$. aureus in saliva $(\mathrm{OR}=8.3)$.

CONCLUSION: This study supports the significance of oral and dental factors while controlling for established medical risk factors in aspiration pneumonia incidence. J Am Geriatr Soc 49:557-563, 2001.

Key words: aspiration pneumonia; oral health; dental risk factors; older veterans

A spiration pneumonia is an important cause of morbidity and mortality in persons age 60 and older, in both independent living and institutionalized populations. ${ }^{1,2}$ In the United States, there are an estimated 200,000 cases of aspiration pneumonia per year, accounting for more than 15,000 deaths. ${ }^{3,4}$ Proportionately, older patients and those with long institutional stays are most often affected. ${ }^{2,5,6}$ Aspiration pneumonia is also an important contributor to added length of stay in Department of Veterans Affairs (VA) hospitals throughout the country. ${ }^{7}$

The oral cavity has long been suspected to be a source of the organisms responsible for aspiration pneumonia. Oral anaerobes have been implicated in particular. ${ }^{3,8-10}$ Collecting samples directly from the trachea, to avoid oral contamination, Bartlett et al. ${ }^{3,8}$ have shown oral anaerobic organisms to be present in sputum. This suggests that a diseased oral cavity would be a particularly likely source of pathogens. ${ }^{11,12}$ The relationship between oral diseases and pulmonary diseases in general has been previously reported. ${ }^{9,3-16}$ While there are few studies relating aspiration pneumonia risk to specific oral diseases, we previously reported that the number of decayed teeth was significantly related to incidence of aspiration pneumonia, while controlling for other important risk factors, including functional status, presence of tube feeding, number of medications, smoking status, and multiple comorbid illnesses. ${ }^{7}$ This current report extends that previous analysis by including additional oral microbiological and immunological factors to further investigate relationships between aspiration pneumonia and oral health status. 


\section{METHODS}

Patients in the outpatient clinics, inpatient wards, and nursing home of the Ann Arbor, Michigan, VA Medical Center, age 55 and older, were recruited for an ongoing, prospective study begun in 1990. The institutional review boards for human subject research of the University of Michigan and the VA Medical Center in Ann Arbor approved the conduct of this study, and all subjects provided informed consent to participate in this study. At entry to the study, no newly enrolled subjects were hospitalized with pneumonia as the admission diagnosis. This study included yearly follow-up visits for dental examinations and prospective medical follow-up for development of pneumonia. Details of data and specimen collection and assay procedures have already been described. ${ }^{17,18}$ Briefly, data collected at the initial and follow-up visits consisted of the following: (1) a face-to-face interview with items for demographic data, detailed medical and dental history of past illnesses and conditions, current conditions, current medications, functional status, xerostomia complaints, dietary intake, health-related behaviors (e.g., tobacco use, alcohol use, personal oral hygiene, dental care utilization, exercise, and sleep patterns), and self-perceptions and beliefs regarding health status; (2) a records review of the medical chart and hospital database; (3) a comprehensive clinical dental examination to assess the status of dentition with respect to oral hygiene, dental caries, periodontal disease, number of teeth, masticatory potential based on number of opposing natural or prosthetic tooth pairs, and presence of removable prostheses. Specimens collected at these visits included (1) saliva for assays of salivary constituents and salivary IgA antibodies to selected periodontopathic and cariogenic organisms and (2) saliva, throat mucosal, and supra- and subgingival plaque samples for detection of selected aerobic and anaerobic plaque species.

After the baseline visit, study participants were seen at yearly intervals for the interview, dental examination, and specimen collection. Medical record reviews were updated after yearly examinations. This annual follow-up continued for up to nine yearly visits, or until the subject's death. A single nurse clinician reviewed the database entries and medical records of hospitalized study participants for pneumonia diagnoses from June 1990 to December 1998. When episodes of pneumonia were identified, the medical record for each incidence was reviewed for evidence of fever, rise in white blood cell count, clinical signs, chest radiograph, presence of pleural fluid or empyema, and positive respiratory fluid cultures or Gram stain. The same panel, consisting of a geriatrician, a geriatric cardiologist, and a pulmonary physician, reviewed and evaluated all suspected cases of aspiration pneumonia. The following criteria were used for pneumonia diagnosis: positive respiratory fluid cultures, an infiltrate visible on the chest radiograph, the pulmonary physician's assessment that aspiration-type pneumonia was present, and clinical findings compatible with the diagnosis of aspiration pneumonia. Clinical findings supporting a diagnosis of aspiration pneumonia included body temperature greater than $99.5^{\circ} \mathrm{F}$; observed aspiration; white blood cell count showing a rise of 5,000 cells $/ \mathrm{mm}^{3}$ or greater; the opinion of the attending physician that pneumonia was present; appropriate auscultatory findings; characteristic symptoms including fever with cough, sputum production, dyspnea, or pleuritic chest pain; or positive pleural fluid cultures. Cases were required to have a chest radiograph examined by the pulmonary physician. Cases considered by the pulmonary physician to have a strong alternate diagnosis or with a chest infiltrate due to other causes, such as pulmonary embolus or infarction, pulmonary fibrosis, or lung cancer, were excluded. Additionally, cases considered to be communityacquired were excluded. Controls were enrolled subjects who did not develop any type of pneumonia, aspiration or nonaspiration, as determined by medical record and chest radiograph review.

Statistical analyses included bivariate and multivariate analyses to test for associations between aspiration pneumonia and the presence of common plaque-and periodontal disease-or dental caries-associated microorganisms, $\operatorname{sg} \mathrm{A}$ antibodies to a panel of periodontal pathogens, presence of selected respiratory pathogens in saliva and throat cultures, clinical oral health measures for hygiene, dental caries and periodontal disease, and previously recognized medical conditions and functional status measures. Statistical significance was set at the .05 level. Two separate multivariate logistic regression models of risk factors for incidence of aspiration pneumonia were constructed. One model evaluated only dentate subjects and included dental variables such as measures of periodontal disease and dental caries, presence of bacteria known to be etiological factors in dental caries and periodontal infections, and medical and functional status variables. A second model included both dentate and edentulous subjects and excluded variables that were specific to dentate subjects (e.g., measures of periodontal disease, dental caries, and dental plaque bacteria).

\section{RESULTS}

Fifty subjects developed aspiration pneumonia during the study period, 28 of whom were dentate. Table 1 presents baseline demographic characteristics for subjects included in these analyses. There are two groupings for the data: one for the 218 dentate subjects and another that includes all 358 subjects (dentate and edentulous). There were significant differences in the incidence of aspiration pneumonia when analyzed by subject's residence status at time of entry in the study (outpatient, inpatient, or nursing home) for the dentate group $(P=.03)$ and the edentulous plus dentate group $(P=.001)$. The age ranges were similar for those with and without aspiration pneumonia in both the dentate and edentulous plus dentate groups. There was no significant relationship between education and aspiration pneumonia. The small number of nonwhite subjects with aspiration pneumonia precluded detection of significant differences in the distributions of aspiration pneumonia incidence by race/ethnicity.

In the dentate subjects, the presence of Porphyromonus gingivalis $(P$. gingivalis) in dental plaque (odds ratio $(\mathrm{OR})=2.7 ; 95 \%$ confidence interval $(\mathrm{CI})=1.3-5.3)$ and of Streptococcus sobrinus (S. sobrinus) (OR $=2.3 ; 95 \%$ $\mathrm{CI}=0.9-5.9)$ and Staphylococcus aureus (S. aureus) in the saliva $(\mathrm{OR}=4.3 ; 95 \% \mathrm{CI}=2.0-9.3)$ was significantly higher in subjects with aspiration pneumonia (Table 2). The dentate subjects with aspiration pneumonia tended to have more decayed teeth $(P=.06)$ and had noticeably higher proportions of subjects with visible dental plaque 
Table 1. Baseline Demographic Characteristics* for Subjects who Were Included in the Logistic Regression Analyses

\begin{tabular}{|c|c|c|c|c|}
\hline & \multicolumn{2}{|c|}{ Dentate Subjects Only } & \multicolumn{2}{|c|}{ Dentate and Edentulous Subjects } \\
\hline & $\begin{array}{l}\text { No Pneumonia } \\
n=190\end{array}$ & $\begin{array}{l}\text { Aspiration Pneumonia } \\
\qquad n=28\end{array}$ & $\begin{array}{l}\text { No Pneumonia } \\
n=308\end{array}$ & $\begin{array}{l}\text { Aspiration Pneumonia } \\
\qquad n=50\end{array}$ \\
\hline \multicolumn{5}{|c|}{ Residence status at entry, $\mathrm{n}(\%)$} \\
\hline Outpatient & $132(91.0)$ & $13(9.0)$ & $181(91.4)$ & $17(8.6)$ \\
\hline Inpatient & $23(82.1)$ & $5(17.9)$ & $43(76.8)$ & $13(23.2)$ \\
\hline Age (range, in years) & $58-90$ & $61-85$ & $58-96$ & $60-93$ \\
\hline \multicolumn{5}{|l|}{ Age categories, $\mathrm{n}(\%)$} \\
\hline$<70$ & $122(89.0)$ & $15(11.0)$ & $204(89.1)$ & $25(10.9)$ \\
\hline $70-79$ & $63(85.1)$ & $11(14.9)$ & $96(83.5)$ & $19(16.5)$ \\
\hline $80+$ & $5(71.4)$ & $2(28.6)$ & $8(57.1)$ & $6(42.9)$ \\
\hline \multicolumn{5}{|l|}{ Education, n (\%) } \\
\hline White & $171(86.8)$ & $26(13.2)$ & $279(86.7)$ & $43(13.3)$ \\
\hline Black & $13(92.9)$ & $1(7.1)$ & $20(80.0)$ & $5(20.0)$ \\
\hline Other & $5(83.3)$ & $1(16.7)$ & $8(88.9)$ & $1(11.1)$ \\
\hline
\end{tabular}

Note: Percentages of subjects in each row for each variable by dentate and pneumonia status are shown in parentheses.

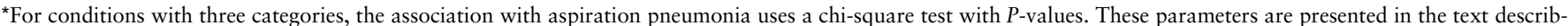
ing this table.

$(\mathrm{OR}=2.1 ; 95 \% \mathrm{CI}=0.9-5.1)$. The presence of $S$. aureus $(\mathrm{OR}=4.3 ; 95 \% \mathrm{CI}=2.0-9.4)$ and $S$. sobrinus $(\mathrm{OR}=$ $2.0 ; 95 \% \mathrm{CI}=0.9-3.7)$ in the saliva among the dentate plus edentulous group was similarly more likely in subjects with aspiration pneumonia. Other oral health characteristics were not remarkably different for those with and without aspiration pneumonia in either group.

Table 3 shows the distributions of selected baseline behavioral, functional, and medical characteristics as a function of baseline dentate status and aspiration pneumonia status at follow-up. There were notably higher proportions of subjects in the dentate group with an episode of aspiration pneumonia who needed help with feeding $(36 \%$, OR $=$ $3.2,95 \% \mathrm{CI}=1.3-7.5)$, were current smokers $(15 \%, P=$ $.08)$, had chronic obstructive pulmonary disease (COPD) $(20 \%, \mathrm{OR}=1.9,95 \% \mathrm{CI}=0.9-3.9)$, had diabetes mellitus $(22.5 \%, \mathrm{OR}=2.2,95 \% \mathrm{CI}=1.1,4.4)$ or had congestive heart failure $(20 \%, \mathrm{OR}=2.1,95 \% \mathrm{CI}=0.8-5.6)$. There were no significant differences in proportions of subjects with aspiration pneumonia based upon reported alcohol consumption $(P=.09)$, needing help brushing $(\mathrm{OR}=$ $1.6,95 \% \mathrm{CI}=0.4-6.2)$, or stroke $(\mathrm{OR}=1.3,95 \% \mathrm{CI}=$ $0.6-3.0)$. In the dentate plus edentulous group, the bivariate patterns for needing help eating, diabetes mellitus, and COPD were similar to those shown for the dentate group, but there were no noteworthy differences based on presence of congestive heart failure.

Two separate multivariate logistic regression models, one limited to the analysis of dentate subjects and a second including both dentate and edentulous participants, were developed for the outcome cumulative incidence of aspiration pneumonia (Table 4). The model restricted to dentate subjects provided estimates for several medical, dental, and bacteriological parameters that were significantly associated with the subsequent diagnosis of aspiration pneumonia. Needing help with feeding was the most prominent parameter with an OR $=13.9$ (95\% CI $=3.2-60.8)$. Significant medical conditions included presence of COPD $(\mathrm{OR}=4.7 ; 95 \% \mathrm{CI}=1.6-14.3)$ and diabetes mellitus $(\mathrm{OR}=3.5 ; 95 \% \mathrm{CI}=1.2-9.8)$. Significant dental variables were number of decayed teeth $(\mathrm{OR}=1.2 ; 95 \% \mathrm{CI}=$ 1.1-1.4, for each additional decayed tooth) and number of functional (dental) units $(\mathrm{OR}=1.2 ; 95 \% \mathrm{CI}=1.02-1.4)$. The presence of $S$. aureus (OR $=7.4 ; 95 \% \mathrm{CI}=1.8-30.5$ ) and of $S$. sobrinus $(\mathrm{OR}=6.2 ; 95 \% \mathrm{CI}=1.4-27.5)$ in the saliva, and the presence of the periodontopathogen $P$. gingivalis in dental plaque $(\mathrm{OR}=4.2 ; 95 \% \mathrm{CI}=1.6-11.3$ ) were also significant. This model had a sensitivity of 0.82 and a specificity of 0.70 at a $P$-level of.10, supporting it as a reasonable fit to these data.

When all subjects were included in the regression model, the significant effects persisted for subjects needing help eating $(\mathrm{OR}=4.7 ; 95 \% \mathrm{CI}=1.9-11.6)$, presence of $\mathrm{COPD}(\mathrm{OR}=2.5 ; 95 \% \mathrm{CI}=1.3-5.0)$, and presence of $S$. aureus $(\mathrm{OR}=8.3 ; 95 \% \mathrm{CI}=2.8-24.7)$ in the saliva. There was a tendency for the risk to be greater in those with diabetes mellitus $(\mathrm{OR}=1.7 ; 95 \% \mathrm{CI}=0.9-3.5)$ although the $95 \%$ CI included the null value. This model had a sensitivity of 0.66 and a specificity of 0.71 at a P-level of .12 .

\section{DISCUSSION}

Our analyses of the cumulative incidence of aspiration pneumonia have provided statistically significant estimates for putative oral health-related risk factors in two clinically plausible and complementary models. These factors include dental caries (number of decayed teeth), presence 
Table 2. Baseline Oral Health Characteristics ${ }^{\star}$ for Subjects who Were Included in the Logistic Regression Analyses

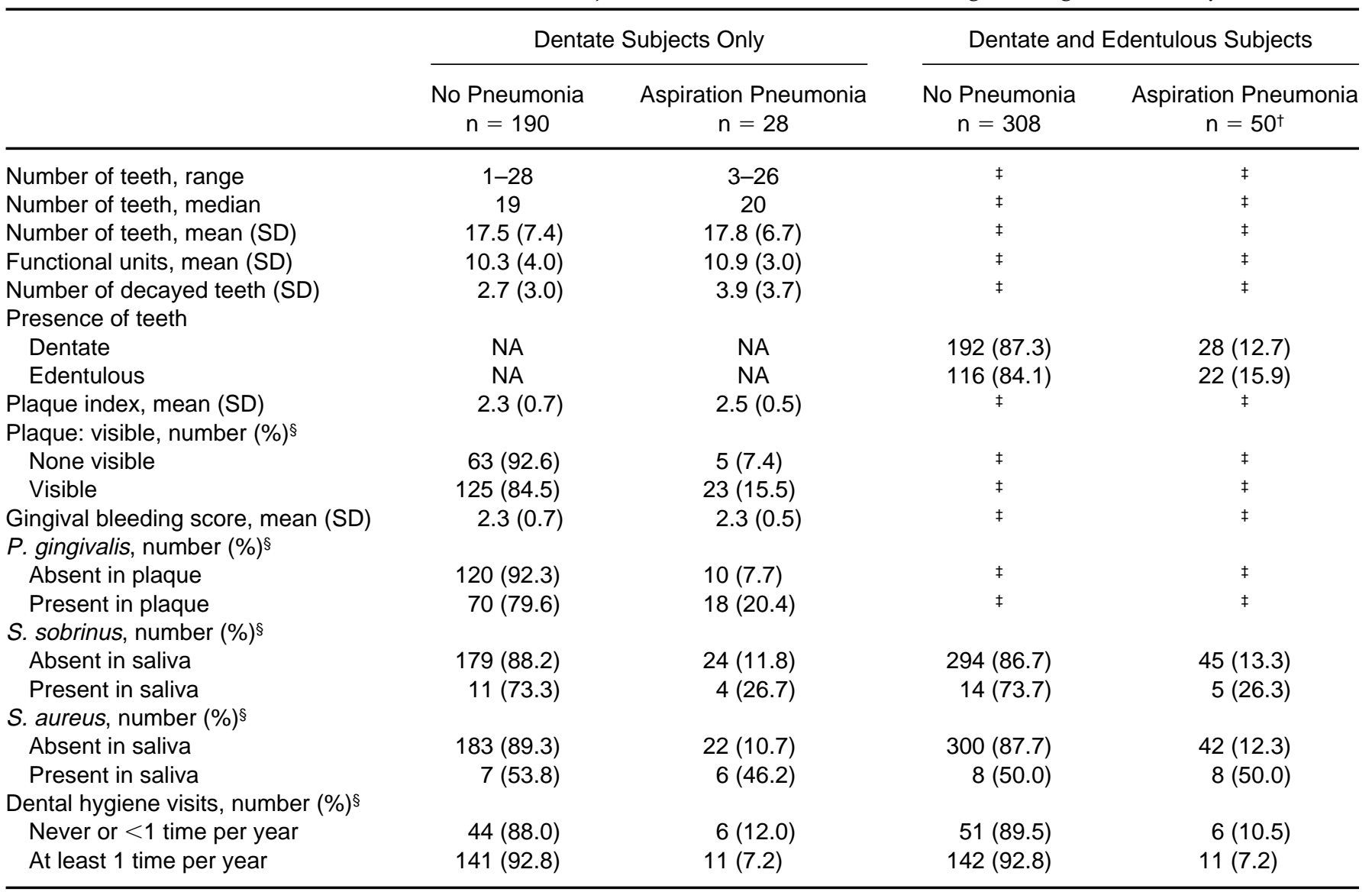

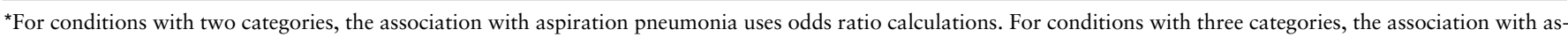
piration pneumonia uses a chi-square test with $P$-values. These parameters are presented in the text describing this table.

†The number of subjects reported for some variables is less than the total numbers due to missing data.

‡Values are identical to those for the dentate subset of subjects.

\$Percentages of subjects in each row for each category of the variable by dentate and pneumonia status are shown in parentheses.

$\mathrm{SD}=$ standard deviation; $\mathrm{NA}=$ not applicable.

of $S$. sobrinus in saliva, the presence in dental plaque of an important periodontal pathogen and Gram-negative anaerobe, $P$. gingivalis, and functional dental units. Bartlett et al. had suggested that the oral cavity could be the source of some of the bacterial species that cause aspiration pneumonia. ${ }^{19}$ Dental and oral factors have previously been implicated in aspiration pneumonia risk, ${ }^{7,9,20,21}$ but there has been limited quantification of the association of specific microbiological parameters in multivariate models that include other established medical risk factors and comorbid illnesses and conditions. The models derived from our analyses included statistically significant effects for risk factors previously recognized as important in the etiology of aspiration pneumonia (needing help eating, a measure of compromised functional status; COPD, an indicator of compromised lung function; and diabetes mellitus, associated with impaired host response) and for clinically and microbiologically related dental/oral factors.

While the model including edentulous patients could not test the effects of factors associated with having teeth, it nevertheless produced estimates that included significant effects for presence of $S$. aureus in the saliva in addition to established risk factors for aspiration pneumonia. The re- sults of these two models are complementary in that the dentate model identifies and quantifies modifiable dental health-related potential risk factors, while the model including edentulous subjects provides estimates that serve to support the credibility of the data and analytic approach used.

Both models include a significant effect for the variable, "needs help eating." Previously in this population of subjects we reported that a dependency upon others for eating was a significant risk factor for aspiration pneumonia $(\mathrm{OR}=20) .^{7}$ This was also found to be true for dental caries in a multivariate model that assessed a comprehensive set of risk factors for aspiration pneumonia. ${ }^{7}$ Our finding for "needs help eating" is consistent with an earlier report describing increased risk for aspiration pneumonia in individuals with compromised functional capacity. ${ }^{4}$ This is consistent with reports of clinical situations where health providers who may be rushed place too much food in the patient's mouth and do not wait for a full swallow. ${ }^{7}$ Langmore et al. ${ }^{7}$ hypothesize that this potential "forcefeeding" might result in unrecognized aspiration of a mixture of saliva, food, or liquid being fed and oral flora. An example of an intervention designed to implement "safe 
Table 3. Baseline Behavioral, Functional, and Medical Status for Selected Conditions ${ }^{*}$ by Aspiration Pneumonia Status at Follow-Up in Subjects who Were Included in the Logistic Regression Analyses

\begin{tabular}{|c|c|c|c|c|}
\hline & \multicolumn{2}{|c|}{ Dentate Subjects Only } & \multicolumn{2}{|c|}{ Dentate and Edentulous Subjects } \\
\hline & $\begin{array}{l}\text { No Pneumonia } \\
\quad \mathrm{n}=190\end{array}$ & $\begin{array}{l}\text { Aspiration Pneumonia } \\
\qquad \mathrm{n}=28\end{array}$ & $\begin{array}{l}\text { No Pneumonia } \\
\quad n=308\end{array}$ & $\begin{array}{l}\text { Aspiration Pneumonia } \\
\qquad \mathrm{n}=50\end{array}$ \\
\hline Time to pneumonia, median days & NA & 174 & NA & 184 \\
\hline \multicolumn{5}{|l|}{ Smoking status } \\
\hline Never smoked & $27(96.4)$ & $1(3.6)$ & $34(97.1)$ & $1(2.9)$ \\
\hline Former smoker & $129(92.1)$ & $11(7.9)$ & $204(92.3)$ & $17(7.7)$ \\
\hline Current smoker & $33(84.6)$ & $6(15.4)$ & $69(81.2)$ & $16(18.8)$ \\
\hline \multicolumn{5}{|l|}{ Alcohol use } \\
\hline Not using & $82(82.8)$ & $17(17.2)$ & $141(82.5)$ & $30(17.5)$ \\
\hline Uses occasionally & 79 (92.9) & $6(7.1)$ & $122(91.7)$ & $11(8.3)$ \\
\hline Uses daily & $28(90.3)$ & $3(9.7)$ & $44(86.3)$ & $7(13.7)$ \\
\hline \multicolumn{5}{|l|}{ COPD } \\
\hline Absent & $155(89.1)$ & 19 (10.9) & $238(88.2)$ & $32(11.8)$ \\
\hline Present & $35(79.6)$ & $9(20.4)$ & $70(79.5)$ & $18(20.5)$ \\
\hline \multicolumn{5}{|l|}{ Congestive heart failure } \\
\hline Absent & $168(90.3)$ & $18(9.7)$ & $266(89.3)$ & $32(10.7)$ \\
\hline Present & $16(80.0)$ & $4(20.0)$ & $32(86.5)$ & $5(13.5)$ \\
\hline \multicolumn{5}{|l|}{ Stroke } \\
\hline Absent & $149(88.2)$ & $20(11.8)$ & $233(86.3)$ & $37(13.7)$ \\
\hline Present & $37(84.1)$ & $7(15.9)$ & 69 (85.2) & $12(14.8)$ \\
\hline \multicolumn{5}{|l|}{ Diabetes mellitus } \\
\hline Absent & $152(89.9)$ & $17(10.1)$ & $241(87.6)$ & $34(12.4)$ \\
\hline Present & $38(77.5)$ & $11(22.5)$ & $67(80.7)$ & $16(19.3)$ \\
\hline \multicolumn{5}{|l|}{ Needs help eating } \\
\hline Absent & $181(88.7)$ & $23(11.3)$ & $291(87.7)$ & $41(12.3)$ \\
\hline Present & $9(64.3)$ & $5(35.7)$ & $17(65.4)$ & $9(34.6)$ \\
\hline \multicolumn{5}{|l|}{ Needs help brushing teeth } \\
\hline Absent & $180(87.8)$ & 25 (12.2) & $290(86.6)$ & $45(13.4)$ \\
\hline Present & $8(80.0)$ & $2(20.0)$ & 14 (82.3) & $3(17.7)$ \\
\hline
\end{tabular}

Note: Percentages of subjects in each row for each variable by dentate and pneumonia status are shown in parentheses.

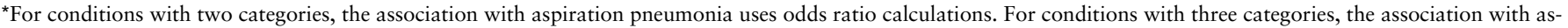
piration pneumonia uses a chi-square test with $P$-values. These parameters are presented in the text describing this table.

$\mathrm{NA}=$ not applicable; COPD $=$ chronic obstructive pulmonary disease.

feeding" is the Silver Spoons Program, begun in the Miami VA Medical Center, where nurses and volunteers have been taught safer feeding techniques..$^{22,23}$

A significant role for COPD in the model is reasonable in view of the likelihood of poor pulmonary clearance in these patients and is consistent with its frequent occurrence as an underlying disease commonly associated with pneumonia. Smoking was not found to be a significant factor associated with aspiration pneumonia in the model, probably reflecting the large number of patients in our study, both with and without COPD, who were past or current smokers.

Diabetes mellitus has been recognized as a common comorbid illness in both nosocomial and communityacquired pneumonia. ${ }^{24-26}$ Hence its inclusion as a covariate in the models strengthens the credibility of our result. Diabetes mellitus is recognized to predispose to infection in general ${ }^{27}$ although this concept has been challenged, both for infection in general ${ }^{28}$ and with respect to pneumonia. ${ }^{5}$ Others have suggested that diabetes mellitus adversely affects host resistance to certain infections, including those associated with Gram-negative anaerobes. ${ }^{29-31}$
Individuals with diabetes mellitus have been observed to have a higher prevalence of Gram-negative bacilli than age- and socioeconomic status-matched control subjects ${ }^{32}$ and are at greater risk for periodontal infection. ${ }^{33,34}$

The presence of $S$. aureus in saliva was found to be significant in both models. S. aureus and other respiratory pathogens can colonize the mouth and their presence would be independent of the presence or absence of teeth. This could explain why $S$. aureus was the only bacterial species monitored that was significantly associated with aspiration pneumonia in both models (Table 4). Components of the oral cavity, such as teeth (particularly cavitated lesions), oral mucosal surfaces, saliva, dental plaque, and denture surfaces, are potential reservoirs for colonization by potential respiratory pathogens. ${ }^{8,10,12,16,35,36} \mathrm{~S}$. aureus is a recognized and increasingly common organism found in nosocomial pneumonia in older people. ${ }^{4,20,37} \mathrm{Oth}$ ers have reported significantly more dental plaque and higher colonization by $S$. aureus (and other respiratory pathogens) of the teeth and oral mucosa of medical intensive care unit (ICU) patients compared with nonhospitalized controls in both a VA hospital ${ }^{38}$ and a community hospital. ${ }^{9}$ 
Table 4. Summary Table of Coefficient Estimates from Logistic Regression Modelling Procedures for Cumulative Incidence of Aspiration Pneumonia

\begin{tabular}{|c|c|c|c|c|c|c|c|c|}
\hline \multirow[b]{2}{*}{ Variables } & \multicolumn{4}{|c|}{$\begin{array}{l}\text { Dentate Subjects Only } \\
\qquad \mathrm{n}=220\end{array}$} & \multicolumn{4}{|c|}{$\begin{array}{l}\text { Dentate and Edentulous Subjects } \\
\qquad \mathrm{n}=358\end{array}$} \\
\hline & $\begin{array}{l}\text { Coefficient } \\
\text { Estimates }\end{array}$ & $\begin{array}{l}\text { Standard } \\
\text { Error }\end{array}$ & $P$-Value* & $\begin{array}{l}\text { Odds Ratio } \\
\text { (95\% Cl) }\end{array}$ & $\begin{array}{l}\text { Coefficient } \\
\text { Estimates }\end{array}$ & $\begin{array}{l}\text { Standard } \\
\text { Error }\end{array}$ & $P$-Value* & $\begin{array}{l}\text { Odds Ratio } \\
(95 \% \mathrm{Cl})\end{array}$ \\
\hline Intercept & -6.62 & 1.28 & $<.001$ & NA & -2.56 & 0.26 & $<.001$ & NA \\
\hline Needs help eating & 2.63 & 0.75 & $<.001$ & $13.9(3.2-60.8)$ & 1.54 & 0.47 & .001 & $4.7(1.9-11.6)$ \\
\hline COPD & 1.55 & 0.56 & .006 & $4.7(1.6-14.3)$ & 0.92 & 0.35 & .009 & $2.5(1.3-5.0)$ \\
\hline Diabetes mellitus & 1.24 & 0.53 & .020 & $3.5(1.2-9.8)$ & 0.55 & 0.36 & .126 & $1.7(0.9-3.5)$ \\
\hline S. aureus presence & 2.0 & 0.73 & .006 & $7.4(1.8-30.5)$ & 2.12 & 0.55 & $<.001$ & $8.3(2.8-24.7)$ \\
\hline$P$. gingivalis presence & 1.44 & 0.50 & .004 & $4.2(1.6-11.3)$ & & & & \\
\hline Number of decayed teeth ${ }^{\dagger}$ & 0.19 & 0.07 & .007 & $1.2(1.1-1.4)$ & & & & \\
\hline S. sobrinus presence & 1.83 & 0.76 & .016 & $6.2(1.4-27.5)$ & & & & \\
\hline Functional units ${ }^{\ddagger}$ & 0.18 & 0.08 & .023 & $1.2(1.02-1.4)$ & & & & \\
\hline
\end{tabular}

${ }^{*} P$-value of the standard normal variable.

tThe odds ratio for the number of decayed teeth should be multiplied by the number of decayed teeth.

‡Functional units are the number of pairs of natural and prosthethic teeth that contact with chewing.

$\mathrm{NA}=$ not applicable; $\mathrm{COPD}=$ chronic obstructive pulmonary disease.

Previous investigators have reported a relationship between periodontal disease and aspiration pneumonia. ${ }^{8,9,12}$ The presence of $P$. gingivalis, an important Gram-negative anaerobic periodontal pathogen ${ }^{39}$ in the supragingival plaque, associates oral colonization by periodontal pathogens with risk for aspiration pneumonia in the dentate subject model. $P$. gingivalis and several other periodontal pathogens are proteolytic organisms capable of degrading fibronectin..$^{40}$ It has been hypothesized that the proteolytic activity of a periodontopathic bacterium could alter the fibronectin-coated oral mucosal epithelial cell surfaces, thereby compromising a protective barrier and enabling colonization of oral mucosal surfaces with potential respiratory pathogens. ${ }^{11,41}$ This result gives additional quantitative support to previous reports and impressions of the importance of periodontal disease as a potential risk factor for aspiration pneumonia. ${ }^{8,9,12}$

The relationship between the number of teeth with dental decay and aspiration pneumonia was shown previously. $7,8,12,13,36$ It is augmented in the present report by the finding of a significant association between the presence of S. sobrinus in saliva and aspiration pneumonia $(\mathrm{OR}=6.2$, Table 4). S. sobrinus is a cariogenic microorganism found in dental plaque..$^{42}$ In addition to its role as a cariogenic organism and previously reported association with dental caries in this population, S. sobrinus has been significantly associated with complaints of xerostomia and a salivary $\mathrm{pH}<6.4$ in these subjects. ${ }^{17}$ This suggests that its relationship to aspiration pneumonia may reflect some aspect of xerostomia in these subjects. Xerostomia had been proposed previously as a possible risk factor for aspiration pneumonia because it would serve to concentrate the number of bacteria per milliliter of saliva. ${ }^{11}$

Data on S. sobrinus as a cause of pneumonia are limited, although it has been noted in collections of anaerobes implicated in aspiration pneumonia and lung abscess. ${ }^{3,8,20}$ Finding S. sobrinus and $P$. gingivalis as significant risk factors associated with aspiration pneumonia does not dic- tate any change in current antibiotic approaches to treatment, since both of these organisms usually are sensitive to penicillin, cephalosporins, and other commonly used antibiotics for aspiration pneumonia. Other adjustments in antibiotic therapy of aspiration pneumonia may be needed in the future as more patients experience changes in oral colonization and as more patients aspirate $S$. aureus or resistant organisms while in the institutional setting.

The interpretation of the finding that functional units are a significant factor in the model is as yet undetermined. As mentioned previously, a functional unit is defined as a pair of teeth (natural or prosthetic) that can contact each other in chewing. ${ }^{43}$ The importance of the number of functional units may reflect availability of a greater surface area for dental plaque load.

The constellation of covariates for the model that includes edentulous participants included all the nondental variables. For each covariate, except diabetes mellitus, the effects were statistically significant. We chose to retain diabetes mellitus in the model because of its clinical relevance and because its removal did not substantially change the model fit or any of the other effect estimates. The estimated effect of diabetes mellitus, while not quite reaching statistical significance at $P=.05$, was nevertheless noteworthy $(\mathrm{OR}=1.7 ; 95 \% \mathrm{CI}=0.9-3.5)$.

Results from this study suggest that various interventions, in addition to the usual intervention of elevating the head of the patient's bed, may be helpful in reducing the incidence of aspiration pneumonia in older patients. Our results support giving high priority to careful training of persons who feed patients and to use of measures to reduce the severity of COPD, such as smoking cessation assistance. Additionally, our results support providing dental care to reduce the dental plaque load and to treat dental caries and periodontal disease. Dental treatment should lead to significant reductions in the presence of Gram-negative anaerobic periodontal pathogens like $P$. gingivalis, cariogenic organisms, cariogenic activity, and 
cavitated lesions. For both dentate and edentulous patients, effective oral hygiene measures could also reduce the presence of $S$. aureus in the oral cavity.

\section{CONCLUSION}

This study provides evidence supporting dental decay, presence of cariogenic bacteria, and periodontal pathogens as potentially important risk factors for aspiration pneumonia. These dental health-related factors were significant in multivariate models after controlling for established medical risk factors.

Reducing aspiration pneumonia incidence may be one outcome of programs to improve oral health in community-living and institutionalized older people. One logical next step would be to conduct further investigations to test for a beneficial effect of oral healthcare programs on the incidence of aspiration pneumonia in older people.

\section{ACKNOWLEDGMENTS}

The authors gratefully acknowledge support from the Department of Veterans Affairs in conducting this project and the assistance of Kathy Curry and Harold Winegarner in data collection and management, Janice Stoll and Neal Van Poperin in conducting the microbiological and immunological assays, and Mary Ann Erlandson in preparation of the manuscript.

\section{REFERENCES}

1. Granton JT, Grossman RF. Community-acquired pneumonia in the elderly patient: Clinical features, epidemiology, and treatment. Clin Chest Med 1993;14:537-553.

2. Niederman MS. Nosocomial pneumonia in the elderly patient: Chronic care facility and hospital considerations. Clin Chest Med 1993;14:479-490.

3. Bartlett JG, Gorbach SL. The triple threat of aspiration pneumonia. Chest 1975;68:560-566.

4. Fein AM. Pneumonia in the elderly: Special diagnostic and therapeutic considerations. Med Clin North Am 1994;78:1015-1033.

5. Skerrett SJ, Niederman MS, Fein AM. Respiratory infections and acute lung injury in systemic illness. Clin Chest Med 1989;10:469-502.

6. Fein AM, Feinsilver SH, Niederman MS. Nonresolving and slowly resolving pneumonia: Diagnosis and management in the elderly patient. Clin Chest Med 1993;14:555-569.

7. Langmore SE, Terpenning MS, Schork A et al. Predictors of aspiration pneumonia: How important is dysphagia? Dysphagia 1998;13:69-81.

8. Bartlett JG, Finegold SM. Anaerobic infections of the lung and pleural space. Am Rev Respir Dis 1974;110:56-77.

9. Scannapieco FA, Mylotte JM. Relationships between periodontal disease and bacterial pneumonia. J Periodontol 1996;67:1114-1122.

10. Terpenning MS. The ten most common questions about aspiration pnuemonia. Infect Dis Clin Pract 1996;5:42-46.

11. Loesche WJ, Baum BJ, Heft MW. New research directions in gerontological aspects of periodontology. In: Ellen RP, ed. Periodontal Care for Older Adults. Toronto: Canadian Scholar's Press, 1992.

12. Mojon P, Budtz-Jorgensen E, Michel JP et al. Oral health and history of respiratory tract infection in frail institutionalized elders. Gerodontology 1997; 14:9-16.

13. Scannapieco FA, Papandonatos GD, Dunford RG. Associations between ora conditions and respiratory disease in a national sample survey population. Ann Periodontol 1998;3:251-256.

14. Hayes C, Sparrow D, Cohen M et al. The association between alveolar bone loss and pulmonary function: The VA Dental Longitudinal Study. Ann Periodontol 1998;3:257-261.
15. Morris JF, Sewell DL. Necrotizing pneumonia caused by mixed infection with Actinobacillus actinomycetemcomitans and Actinomyces israelii: Case report and review. Clin Infect Dis 1994;18:450-452.

16. Megran DW, Chow AW. Bacterial aspiration and anaerobic pleuro-pulmonary infections. In: Sande MA, Hudson LD, Root RK, eds. Respiratory Infections. New York: Churchill Livingstone, 1986, pp 269-292.

17. Loesche WJ, Abrams J, Terpenning MS et al. Dental findings in geriatric populations with diverse medical backgrounds. Oral Surg Oral Med Oral Pathol Oral Radiol Endod 1995;80:43-54.

18. Terpenning M, Bretz W, Lopatin D et al. Bacterial colonization of saliva and plaque in the elderly. Clin Infect Dis 1993;16:S314-S316.

19. Bartlett JG, Gorbach SL, Finegold SM. The bacteriology of aspiration pneumonia. Am J Med 1974;56:202-207.

20. Finegold SM. Aspiration pneumonia. Rev Infect Dis 1991;13:S737-S742.

21. Bartlett JG, Finegold SM. Anaerobic pleuropulmonary infections. Medicine 1972;51:413-450.

22. Musson ND, Kincaid J, Ryan P et al. Nature, nurture, nutrition: Interdisciplinary programs to address the prevention of malnutrition and dehydration. Dysphagia 1990;5:96-101.

23. Musson ND, Frye GD, Nash M. Silver spoons: Supervised volunteers provide feeding of patients [see comments]. Geriatr Nurs 1997;18:18-19.

24. Gentry LO, Rodriguez-Gomez G, Kohler RB et al. Parenteral followed by oral ofloxacin for nosocomial pneumonia and community-acquired pneumonia requiring hospitalization. Am Rev Respir Dis 1992;145:31-35.

25. Valdez R, Narayan KM, Geiss LS et al. Impact of diabetes mellitus on mortality associated with pneumonia and influenza among non-Hispanic black and white U.S. adults. Am J Public Health 1999;89:1715-1721.

26. Ewig S, Torres A. Severe community-acquired pneumonia. Clin Chest Med 1999;20:575-587.

27. Finegold SM. Host factors predisposing to anaerobic infections. FEMS Immunol Med Microbiol 1993;6:159-163.

28. Kaslow RA. Infections in diabetics. In: Harris MI, ed. Diabetes in America. Washington, DC: U.S. Government Printing Office, 1985, pp 1236-1240.

29. Rayfield EJ, Ault MJ, Keusch GT et al. Infection and diabetes: The case for glucose control. Am J Med 1982;72:439-450.

30. Wheat LJ. Infection and diabetes mellitus. Diabetes Care 1980;3:187-197.

31. Lewis RP, Sutter VL, Finegold SM. Bone infections involving anaerobic bacteria. Medicine 1978;57:279-305.

32. Mackowiak PA, Martin RM, Jones SR et al. Pharyngeal colonization by Gram-negative bacilli in aspiration-prone persons. Arch Intern Med 1978; 138:1224-1227.

33. Salvi GE, Lawrence HP, Offenbacher S et al. Influence of risk factors on the pathogenesis of periodontitis. Periodontol 2000 1997;14:173-201.

34. Nelson RG, Shlossman M, Budding LM et al. Periodontal disease and NIDDM in Pima Indians. Diabetes Care 1990;13:836-840.

35. Estes RJ, Meduri GU. The pathogenesis of ventilator-associated pneumonia: I. Mechanisms of bacterial transcolonization and airway inoculation. Intensive Care Med 1995;21:365-383.

36. Mojon P, Rentsch A, Budtz-Jorgensen E et al. Effects of an oral health program on selected clinical parameters and salivary bacteria in a long-term care facility. Eur J Oral Sci 1998;106:827-834.

37. Yoshikawa TT, Norman DC. Bacterial pneumonia. In: Yoshikawa TT, Norman DC, eds. Aging and Clinical Practice: Infectious Diseases. Diagnosis and Treatment. New York: Igaku-Shoin, 1991, pp 108-126.

38. Scannapieco FA, Stewart EM, Mylotte JM. Colonization of dental plaque by respiratory pathogens in medical intensive care patients. Crit Care Med 1992;20:740-745.

39. Loesche WJ, Syed SA, Schmidt E et al. Bacterial profiles of subgingival plaques in periodontitis. J Periodontol 1985;56:447-456.

40. Wikstrom M, Linde A. Ability of oral bacteria to degrade fibronectin. Infect Immun 1986;51:707-711.

41. Woods DE, Straus DC, Johanson WG Jr. et al. Role of fibronectin in the prevention of adherence of Pseudomonas aeruginosa to buccal cells. J Infect Dis 1981;143:784-790.

42. Loesche WJ. Dental Caries: A Treatable Infection. Grand Haven, MI: Automated Diagnostic Documentation, Inc., 1993.

43. Hildebrandt GH, Loesche WJ, Lin CF et al. Comparison of the number and type of dental functional units in geriatric populations with diverse medical backgrounds. J Prosthet Dent 1995;73:253-261. 